BARBOSA, C. P.; et al. A utilização de jogos como metodologia de ensino da Matemática: uma experiência com alunos do $6^{\circ}$ ano do Ensino Fundamental

\title{
A UTILIZAÇÃO DE JOGOS COMO METODOLOGIA DE ENSINO DA MATEMÁTICA: UMA EXPERIÊNCIA COM ALUNOS DO $6^{\circ}$ ANO DO ENSINO FUNDAMENTAL
}

\author{
Cirléia Pereira Barbosa ${ }^{1}$ \\ Augusto Elias Lima ${ }^{2}$ \\ Roberto Costa Neto ${ }^{3}$ \\ Suyara Santos ${ }^{4}$
}

\section{RESUMO}

O presente trabalho tem como objetivo apresentar os resultados de uma experiência envolvendo o jogo como metodologia de ensino de Matemática - realizada na Educação Básica. A partir da literatura estudada, acredita-se que jogo é um instrumento que centraliza o aluno no processo de ensino e aprendizagem, em que os conhecimentos podem ser obtidos ou fixados na elaboração de soluções para situações problematizadoras presentes no jogo. Com a intenção de exemplificar sua abordagem em sala de aula, foi aplicado o Jogo da Velha em uma turma do sexto ano do Ensino Fundamental de uma escola pública da cidade de Formiga (MG). O Jogo da Velha tem por finalidade trabalhar o cálculo mental, o raciocínio lógico e a percepção visual dos discentes. Os resultados mostraram que o jogo contribuiu para a fixação do cálculo mental nos estudantes, para o desenvolvimento da capacidade de abstração e raciocínio lógico, para a socialização e cooperação dos alunos no decorrer da atividade, para o diagnóstico de possíveis concepções errôneas e para o aprendizado docente dos pesquisadores.

Palavras-chave: Matemática. Jogo de estratégia. Cálculo mental.

\section{THE USE OF GAMES AS A MATHEMATICS TEACHING STRATEGY: AN EXPERIENCE WITH STUDENTS ON THE $6^{\text {TH }}$ GRADE OF ELEMENTARY SCHOOL}

\begin{abstract}
The following work has the objective to present the results of an experience - regarding the use of games as a teaching method of Mathematics - applied to Basic Education. From the studied literature, it's believed that games are an instrument that centralizes the students in the teaching and learning process, in which knowledge can be obtained or fixed in the elaboration of solutions to problem situations presented in a game. In order to illustrate its use in the

\footnotetext{
${ }^{1}$ Mestre em Educação Matemática pela Universidade Federal de Ouro Preto (UFOP), pesquisadora e professora do Instituto Federal de Educação, Ciência e Tecnologia de Minas Gerais (IFMG) - Campus Formiga. E-mail: cirleia.barbosa@ifmg.edu.br.

${ }^{2}$ Graduando do curso de Licenciatura em Matemática pelo IFMG - Campus Formiga. E-mail: elias.lima.a@hotmail.com.

${ }^{3}$ Licenciado em Matemática pelo IFMG - Campus Formiga. E-mail: robbertokostta@yahoo.com.br.

${ }^{4}$ Graduanda do curso de Licenciatura em Matemática no IFMG - Campus Formiga. E-mail: suyara.santos@hotmail.com.
} 
BARBOSA, C. P.; et al. A utilização de jogos como metodologia de ensino da Matemática: uma experiência com alunos do $6^{\circ}$ ano do Ensino Fundamental

classroom, the hash game was applied to a class of the $6^{\text {th }}$ year of elementary school, in a public school in the city of Formiga, MG, Brazil. The hash game has the goal to work mental calculation, logical thinking and visual perception of students. The results show that the game contributed for the settling of mental calculation on students, for the developing of abstraction and logical thinking capabilities, for the socialization and cooperation between students during the activity, for the diagnosis of possible erroneous conceptions and for the teaching learning for the researchers.

Keywords: Mathematics. Strategy game. Mental calculations.

\section{INTRODUÇÃO}

O jogo é uma atividade histórica do homem. De acordo com Menezes e Fossa (2004), sua história se confunde com a história do homem.

A relação do jogo com a Matemática também tem longos anos de existência. Desde a Antiguidade, os jogos trabalhavam habilidades matemáticas, como por exemplo, a lógica, o raciocínio rápido, a percepção de formas e tamanhos, etc. (MENEZES; FOSSA, 2004). De acordo com esses autores, uma das maneiras de desenvolver tais habilidades seria durante disputas judiciais de alguns povos primitivos. Nessas competições, os argumentos eram expostos na forma de música envolvendo enigmas a serem decifrados pelo oponente.

A ideia de utilizar o jogo como metodologia de ensino, segundo Grando (2000), já era praticada por Platão (428-7 a.C a 348-7 a.C) ao ensinar a seus discípulos através de jogos de palavras ou de jogos lógicos. A autora acrescenta que as discussões teóricas sobre o uso dessa metodologia no ensino e na aprendizagem iniciou no século XVII. A partir de então, o jogo inseriu-se no âmbito escolar de diferentes maneiras.

Os Parâmetros Curriculares Nacionais (BRASIL, 1998), documento que tem o objetivo de auxiliar na elaboração de currículos da Educação Básica, descreve o jogo como um desafio genuíno que proporciona interesse e prazer. Nesse caso, o desafio para o aluno estimula-o a uma ação, uma vez que ele analisa as suas jogadas e as do adversário, elabora, verifica e modifica estratégias.

Nesse sentido, as situações vivenciadas durante o jogo exigem do aluno coordenar diferentes pontos de vista, estabelecer diversas relações, resolver conflitos e criar estratégias em busca de soluções. Para o professor, a reflexão do aluno acerca do jogo é um momento propício de evidenciar os conceitos trabalhados, regularidades presentes e aplicação a outras situações (GRANDO, 2000). 
BARBOSA, C. P.; et al. A utilização de jogos como metodologia de ensino da Matemática: uma experiência com alunos do $6^{\circ}$ ano do Ensino Fundamental

O objetivo deste artigo é, a partir da literatura sobre a utilização de jogos como metodologia de ensino, relatar uma experiência com o Jogo da Velha e os resultados obtidos ao aplicá-lo em uma turma de alunos do sexto ano do Ensino Fundamental de uma escola pública de Formiga (MG). A proposta foi desenvolvida durante uma disciplina cursada na graduação e orientada pela primeira autora deste trabalho.

Optamos por trabalhar um jogo no sexto ano do Ensino Fundamental que prioriza o cálculo mental, devido à dificuldade observada nos estudantes dessa série na realização de fatos matemáticos e sua importância para o desenvolvimento do aluno para outros conteúdos matemáticos. Conforme presente em Brasil (1998, p. 114) quanto ao estudo do cálculo: “justifica-se pelo fato que é uma atividade básica para o desenvolvimento das capacidades cognitivas do aluno".

Ao docente aguarda-se trazer uma possibilidade de trabalhar o cálculo mental em sala de aula através de uma atividade que difere das convencionais, normalmente baseadas em aplicação de exercícios.

\section{A UTILIZAÇÃO DE JOGOS NO ENSINO DA MATEMÁTICA}

Os jogos são exemplos de atividades que envolvem várias habilidades matemáticas, como a lógica, a memória, a percepção visual, além do que, conteúdos matemáticos específicos podem ser trabalhados. É, portanto, uma possibilidade utilizá-lo em sala de aula.

A partir da reflexão do professor sobre a metodologia da aula com jogo, de tal maneira que essa tenha propósitos dirigidos a desenvolver um novo conceito ou fixar um conteúdo, o jogo, conforme Grando (2000), é definido como jogo pedagógico.

Na utilização do jogo em sala de aula, num primeiro momento, é típica a motivação dos alunos para participarem da atividade, visto que é intrínseco ao jogo sua prazerosidade. Nesse sentido, propicia-se, desde já, uma das condições para aprendizagem dos alunos, pressupondo que "o aprendiz manifeste uma disposição de relacionar um novo material de maneira substantiva e não arbitrária a sua estrutura cognitiva" (MOREIRA; MASSINI, 2011, p. 23).

Ainda sobre a participação dos alunos em aula com jogos, Grando (2000) considera que a atitude revelada pelos discentes - enquanto realizam jogadas - são as mesmas esperadas na construção do conhecimento escolar. De acordo com a autora: 
BARBOSA, C. P.; et al. A utilização de jogos como metodologia de ensino da Matemática: uma experiência com alunos do $6^{\circ}$ ano do Ensino Fundamental

Espera-se um aluno participativo, envolvido na atividade de ensino, concentrado, atento, que elabore hipóteses sobre o que interage, que estabeleça soluções alternativas e variadas, que se organize segundo algumas normas e regras e, finalmente, que saiba comunicar o que pensa, as estratégias de solução de seus problemas. (GRANDO, 2000, p. 17).

Nesse sentido, a atitude dos alunos enquanto jogam assemelha-se ao contexto de resolução de problemas, como afirmado por Grando (2000). O aluno representa a situaçãoproblema estabelecida pelo jogo com suas regras e o indivíduo busca táticas para vencê-lo, portanto, solucionar o problema (Ibidem).

E ainda, o uso de jogos no processo de ensino e aprendizagem da Matemática pode proporcionar aos alunos o desenvolvimento de ações como, tentar, observar, analisar, conjecturar e verificar, que contribuem para o raciocínio lógico, um dos objetivos da Matemática no Ensino Fundamental (BORIN, 2007).

Outro benefício dos jogos é a socialização do aluno no decorrer de sua execução. Brasil (1998) justifica a utilização de convenções e regras dos jogos no apoio à integração do discente no mundo social bastante complexo e os primeiros contatos com futuras teorizações.

No ambiente do jogo deve ser característico o diálogo entre os alunos e entre aluno e professor. Strapason e Bisognin (2013) expõem que esses momentos para o discente são oportunidades de receber auxílio, tanto dos colegas quanto do professor.

No desenvolvimento do jogo o docente pode assumir diferentes funções: observador, juiz, organizador, questionador, mas sempre sendo por meio do jogo um elo entre os alunos e o conhecimento (GRANDO, 2000). Segundo a autora, outro papel fundamental do docente no decorrer das situações do jogo refere-se ao processo de sistematização, no qual para os alunos o conceito trabalhado é ressaltado, algumas observações são instigadas no sentido de atingir os objetivos da atividade.

Apoiamos na literatura consultada para o planejamento, execução e reflexão da atividade desenvolvida com alunos do sexto ano do Ensino Fundamental envolvendo o Jogo da Velha.

Autores como Grando (2000) e Nacarato (2005) reiteram a importância do processo de sistematização em atividades envolvendo o uso de materiais didáticos manipuláveis, no caso da presente pesquisa, o jogo. Assim, no planejamento foi reservado um tempo para as discussões após a execução do jogo pelos alunos, devido à tomada de consciência da importância desse processo que evidencia a ligação do material ao conteúdo explorado. 
BARBOSA, C. P.; et al. A utilização de jogos como metodologia de ensino da Matemática: uma experiência com alunos do $6^{\circ}$ ano do Ensino Fundamental

Brasil (1998, p. 35) relaciona o jogo a "[...] um fazer sem obrigação externa e imposta, mas demanda exigências, normas e controle." Assim, deixamos livre a participação dos discentes na atividade proposta, no entanto, prezamos pelo comportamento e organização no seu desenvolver.

\subsection{Jogos de Cálculo Mental}

Como defende Grando (2000, p. 47): “O cálculo mental está centrado no fato de que um mesmo cálculo pode ser realizado de diferentes formas." Nesse raciocínio, a autora descreve a resolução de problemas de maneira criativa, no encontro de respostas e não fixadas em um único algoritmo. Gali ([19--] apud GRANDO, 2000, p. 48-49) exemplifica uma situação:

\footnotetext{
Saber que 35 é o resultado de 7 por 5 , é saber muito pouca coisa. O conhecimento verdadeiro do 35 , é uma espécie de intuição de todas as possibilidades de se chegar ao número 35 , por numerosas que sejam. 35 é também 25 mais 10, é também 10 mais 10 mais 10 mais 5 , etc ... e também há que intuir as possibilidades de 35 para dar 70, que não cabe um número exato de vezes em 100, etc.
}

A satisfação do discente ao estabelecer diferentes estratégias de cálculo mental, estimula-o a ter uma postura mais positiva em relação à Matemática, favorece a generalização numérica, a imaginação e a memorização (GRANDO, 2000).

Além dessas habilidades citadas pela autora, Brasil (1998, p. 114) complementa que "[...] favorece o desenvolvimento da criatividade, da capacidade para tomar decisões e de atitudes de segurança para resolver problemas numéricos cotidianos.”

O uso de atividades de cálculo mental não dispensa registros por parte dos alunos, uma vez que o registro é fundamental para o processo de formalização dos conteúdos matemáticos, além de ser - para o professor - um instrumento de avaliação e análise dos objetivos da aula.

Sobre a ação do professor em atividades de cálculo mental, esse deve conduzir os discentes a estabelecer relações entre diferentes aspectos das atividades na elaboração de procedimentos pessoais de cálculo pelos estudantes (PARRA, 1996 apud GRANDO, 2000).

Com o intuito de desenvolver o cálculo mental nos alunos, uma das habilidades matemáticas fundamentais para o $6^{\circ}$ ano, optamos pela aplicação do Jogo da Velha.

O jogo e a experiência realizada com os alunos serão apresentados a seguir. 
BARBOSA, C. P.; et al. A utilização de jogos como metodologia de ensino da Matemática: uma experiência com alunos do $6^{\circ}$ ano do Ensino Fundamental

\section{DESCRIÇÃO DO CASO}

A atividade foi aplicada no dia 01/08/2014 em uma escola pública de Formiga (MG), que atende a alunos do Ensino Fundamental e Ensino Médio. A escola fica no centro da cidade e por este motivo recebe alunos de vários bairros. É, então, uma escola com uma variedade de perfis sociais, afetivos e comportamentais.

Os envolvidos foram 22 alunos de uma turma do sexto ano do Ensino Fundamental matriculados no turno vespertino. A professora de Matemática era supervisora de estágio de um dos pesquisadores.

O objetivo da atividade foi desenvolver o cálculo mental, o raciocínio lógico e a percepção visual dos alunos.

O Jogo da Velha ${ }^{5}$ tem como objetivo desenvolver o cálculo mental das operações de adição, subtração, multiplicação, divisão e potenciação, o raciocínio lógico e a percepção visual. É indicado para alunos do sexto ano do Ensino Fundamental por abordar as quatro operações fundamentais (adição, subtração, multiplicação, divisão) e a potenciação, operações as quais são revisadas e ensinadas nesta série.

O jogo desenvolve-se em duplas e é composto por peças do seguinte tipo:

a) um tabuleiro quadrado de lado $18 \mathrm{~cm}$, dividido em 9 quadrados de lado $6 \mathrm{~cm}$;

b) trinta e seis fichas quadradas de lado $4 \mathrm{~cm}$ com os números; $0,1,2,3,4,5,6,7,8$, $9,10,11,12,13,14,15,16,18,20,21,24,25,27,28,30,32,35,36,40,42,45$, $48,50,54,60,64$

c) dez círculos de raio $1,5 \mathrm{~cm}$ (cinco de cada cor);

d) dois cubos de aresta 2,5 cm cujas faces têm, respectivamente, os números 1, 2, 3, 4, 5,6 e $5,6,7,8,9,10$.

\footnotetext{
${ }^{5}$ Baseado em: UNIVERSIDADE SEM FRONTEIRAS. Atividades de laboratório de ensino de matemática. Maringá, PR, 2009. p. 10-12.
} 
BARBOSA, C. P.; et al. A utilização de jogos como metodologia de ensino da Matemática: uma experiência com alunos do $6^{\circ}$ ano do Ensino Fundamental

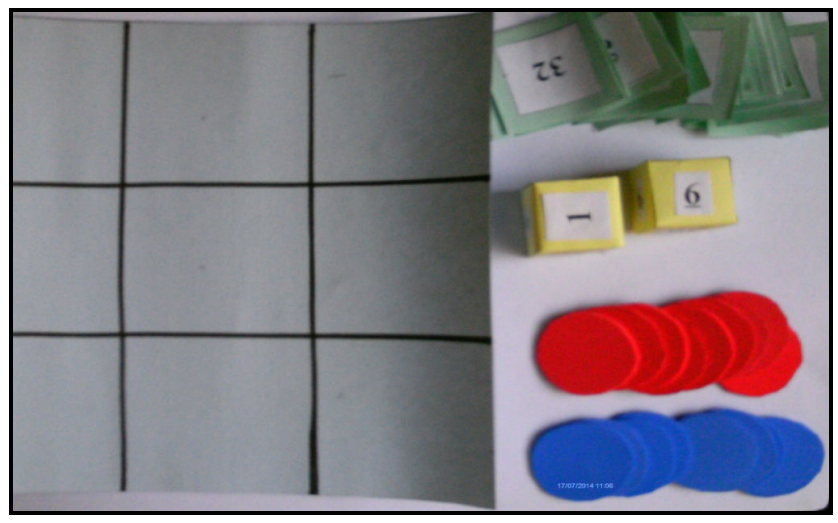

Figura 1 - Peças do Jogo da Velha

Fonte: Fotograda pelos autores.

As regras do Jogo da Velha são as seguintes: cada jogador escolhe a cor dos círculos com a qual deseja jogar. Em seguida, a dupla coloca, aleatoriamente, nove fichas numeradas no tabuleiro, uma em cada espaço. Depois, definem quem inicia o jogo. O primeiro jogador lança os dois dados. Ao ver os números que "caíram", o aluno deve pensar mentalmente nas cinco operações matemáticas (adição, subtração, multiplicação, divisão ou potenciação), para observar se o resultado de uma delas corresponde a um número não marcado nas fichas do tabuleiro. Se o jogador identificar o resultado de uma das operações em um número não marcado nas fichas do tabuleiro, ele deve anunciar a operação e o resultado ao adversário e colocar uma peça de sua cor sobre a ficha. Do contrário, passa-se a vez. O jogo termina quando um dos jogadores marcar três "casas" seguidas, sejam na horizontal, na vertical ou diagonal.

Adicionamos três regras que não constavam no material original. A saber:

a) se o adversário verificar que o resultado de uma operação anunciada pelo jogador está incorreto, ele deve retirar uma das peças de seu oponente do tabuleiro. Nesse caso, se o tabuleiro não estiver marcado alguma peça da cor do jogador, o adversário marca uma peça qualquer de sua cor sobre uma das fichas. Essa regra foi adicionada com o objetivo de despertar a atenção dos alunos, pois cada um deve observar as jogadas do seu oponente para saber se o resultado está coerente com os números sorteados nos dados;

b) se restar somente uma casa vazia no tabuleiro, os dois jogadores têm três tentativas para preenchê-la utilizando os dois dados, do contrário, os jogadores discutem 
BARBOSA, C. P.; et al. A utilização de jogos como metodologia de ensino da Matemática: uma experiência com alunos do $6^{\circ}$ ano do Ensino Fundamental

entre si as possíveis operações e números que darão o resultado da ficha não marcada no tabuleiro. Os jogadores escolhem - a partir dessa discussão - um número para ser fixado em um dado e começam a jogar somente com o outro dado a procura do resultado da ficha não marcada no tabuleiro. Essa regra foi criada com o objetivo de promover o término do jogo quando restasse somente um número não marcado no tabuleiro;

c) a cada rodada, as nove fichas numeradas e usadas devem ser descartadas. Definem-se, então, quatro rodadas de tal maneira que se utilizem todas as 36 fichas numeradas. O objetivo dessa regra era utilizar todos os números das fichas numeradas, evitando o uso repetitivo de fichas nas rodadas jogadas.

A atividade com o Jogo da Velha foi planejada para duas horas/aula (100 minutos) e envolveu as seguintes etapas:

\section{1 - Apresentação das peças do jogo}

O objetivo era destacar as formas das peças do jogo, podendo contribuir para a percepção visual do aluno de algumas formas geométricas planas (quadrado e círculo) e espaciais (cubo). A proposta era perguntar quais formas geométricas os alunos observam nas peças do jogo.

\section{2 - Apresentação das regras do jogo}

Além de apresentar as regras do jogo, solicitamos aos alunos que registrassem em uma folha as operações elaboradas por eles e pelos adversários.

\section{3 - Desenvolvimento do jogo pelos alunos}

Nesta etapa, quando necessário, buscamos esclarecer dúvidas sobre os conteúdos trabalhados no jogo ou sobre suas regras e monitorar a realização do registro por parte dos estudantes.

\section{4 - Discussão das operações realizadas pelos alunos}

O objetivo desta etapa era apresentar para toda a turma as operações registradas pelos colegas e outras possíveis no encontro de determinados resultados presentes nas fichas do jogo. Esta atividade foi desenvolvida no quadro-negro com o acompanhamento dos alunos. 
BARBOSA, C. P.; et al. A utilização de jogos como metodologia de ensino da Matemática: uma experiência com alunos do $6^{\circ}$ ano do Ensino Fundamental

\section{5 - Questionário}

Aplicamos um questionário aos alunos e à professora da turma com o objetivo de recolher informações e opiniões a respeito da aplicação do Jogo da Velha e de atividades com jogos em sala de aula. O questionário também foi uma maneira de avaliar os alunos no desenvolvimento do jogo.

A primeira aula foi destinada à apresentação das peças do jogo, das regras e seu desenvolvimento pelos alunos (etapas 1, 2, 3). A segunda aula foi reservada à discussão das operações realizadas pelos discentes e à aplicação do questionário (etapas 4 e 5).

No primeiro momento da aplicação da atividade, solicitamos que os alunos sentassem em duplas. Foram formadas onze duplas de alunos. O material do jogo e uma folha contendo suas regras e um quadro para registro da dupla também foram entregues.

No início, os discentes fizeram o reconhecimento das peças do jogo, manuseando-as. Perguntamos aos alunos quais formas geométricas eles observaram nas peças distribuídas. As respostas obtidas foram círculo e quadrado. O cubo - forma do dado do jogo - não foi citado pelos discentes.

As regras do jogo foram lidas com o acompanhamento dos alunos que, a princípio, não manifestaram dúvidas quanto às regras estabelecidas. Também explicamos como os alunos deveriam registrar suas jogadas.

A primeira execução do jogo necessitou de interferências dos autores deste artigo. Dúvidas ocorreram sobre o procedimento a ser adotado para iniciar o jogo, por exemplo, houve as perguntas: Quantas fichas com números vou usar? Onde vou colocá-las? Porque os círculos têm cores diferentes? Posso fazer o registro de caneta ou lápis? Entendemos que essas dúvidas iniciais eram normais, uma vez que não conheciam o jogo. A partir da segunda rodada, os alunos começaram a realizar a atividade com mais autonomia, com menor número de interferências. Durante todo o tempo de execução da atividade, tivemos um bom comportamento dos discentes, pois demonstraram atenção ao jogo.

Começamos a segunda aula desenhando na lousa uma tabela com duas colunas, uma de operações e outra de resultados presentes nas fichas do jogo. Para cada resultado, perguntávamos aos alunos quais operações foram usadas e as registrávamos na tabela. A professora permaneceu na sala durante toda a atividade, observando a turma.

Houve uma expressiva participação dos alunos no desenvolvimento da atividade, pois se mostraram entusiasmados em manifestar as operações por eles realizadas. Em certos 
BARBOSA, C. P.; et al. A utilização de jogos como metodologia de ensino da Matemática: uma experiência com alunos do $6^{\circ}$ ano do Ensino Fundamental

momentos, necessitávamos pausar a discussão, pois a maioria dos alunos queria expor simultaneamente as suas ideias.

Em um segundo momento da aula, distribuímos os questionários para os alunos, solicitando que respondessem às questões com sinceridade.

Os resultados obtidos durante a execução da atividade com o Jogo da Velha são apresentados na próxima seção.

\section{DISCUSSÃO DOS RESULTADOS}

Os resultados encontrados foram obtidos por meio de registros dos alunos durante o desenvolvimento da atividade e das respostas aos questionários ${ }^{6}$.

A cooperação e socialização dos alunos ao desenvolver o jogo foi uma característica na maioria das duplas. Apesar da particularidade do jogo de competição e existir no Jogo da Velha a regra: "se um colega anunciar uma operação que não dê como resultado valores vazios do tabuleiro o adversário ganha o direito de retirar uma de suas fichas do tabuleiro", havia nas duplas uma preocupação anterior de respeitar as dificuldades em Matemática um do outro. Em várias situações, quando um aluno percebia que o resultado apresentado pelo seu adversário não era condizente à operação realizada, solicitava a correção do resultado e aguardava o seu adversário pensar novamente na operação. Na falha da autocorreção do adversário, a referida regra do jogo era aplicada e, posteriormente, o colega dizia a justificativa do erro do adversário.

Nesse sentido, um aluno relatou no questionário:

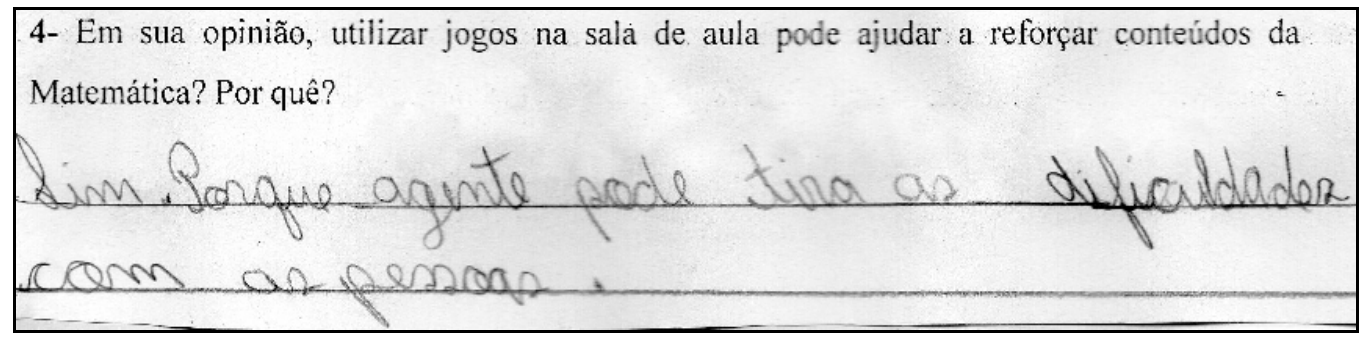

Figura 2 - Resposta do Aluno 1 a Questão 4 do questionário dos alunos Fonte: Imagem digitalizada pelos autores.

\footnotetext{
${ }^{6}$ Os critérios para a seleção das respostas dos alunos foram: a) Respostas com justificativas; b) Coerência da resposta do aluno a pergunta realizada, analisando se a resposta é devidamente condizente a pergunta; c) Respostas que possibilitam fazer conexão com a parte teórica do relato de experiência.
} 
BARBOSA, C. P.; et al. A utilização de jogos como metodologia de ensino da Matemática: uma experiência com alunos do $6^{\circ}$ ano do Ensino Fundamental

Estes momentos proporcionados pelo jogo corroboram a socialização do jogo de regras defendida por Brasil (1998) e coerente ao que diz Strapason e Bisognin (2013, p. 590) quanto à oportunidade de “[...] receber auxílio de seus colegas de grupo e do professor".

Ainda no decorrer do Jogo da Velha percebemos nas duplas antecipações dos alunos sobre os possíveis resultados do jogo. Houve comentários dos estudantes do tipo: "Posso vencer se ocupar esta casa", "Se ocupar esta casa prejudico meu colega de vencer", "A minha possibilidade de vencer é pelas diagonais do tabuleiro". Através destas previsões dos alunos verifica-se que a percepção visual e o raciocínio lógico do aluno foram trabalhados.

Estas antecipações e previsões, em concordância com Grando (2000), dependem de uma situação imaginária, desenvolvendo a capacidade de abstração do aluno, essencial para compreender conceitos e regularidades da Matemática.

Abaixo seguem algumas fotos retiradas durante a aplicação do Jogo da Velha.

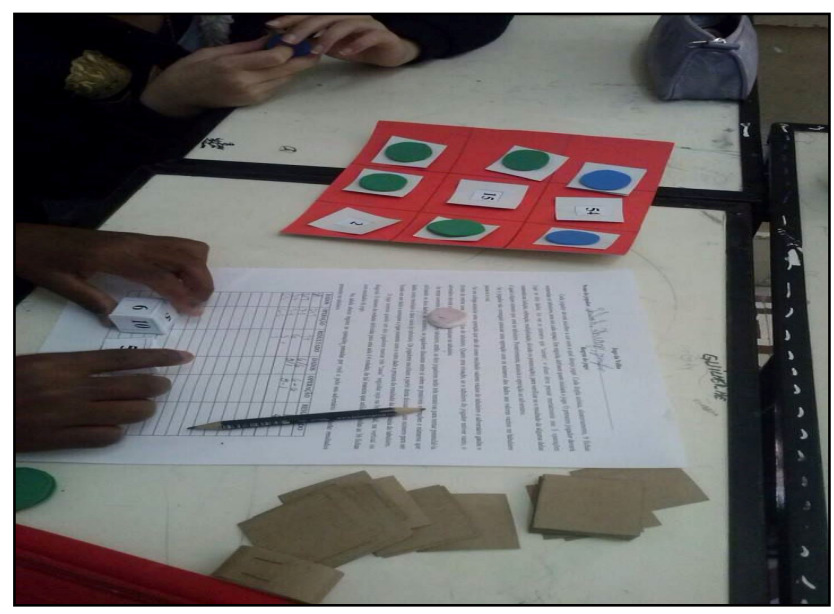

Figura 3 - Aplicação do Jogo da Velha Fonte: Fotograda pelos autores.

O desenvolvimento do cálculo mental - principal objetivo do jogo - foi verificado através da observação dos discentes na execução do Jogo da Velha e nos depoimentos dados por eles no questionário. A cada jogada, exigia-se do aluno um tempo para pensar mentalmente na operação com os números obtidos nos dados para associá-la ao resultado disponível no tabuleiro. Assim, os discentes treinaram vários fatos matemáticos, a memorização e o desenvolvimento de seu raciocínio para realizar cálculos, como seguem nas respostas apresentadas no questionário seguinte. 
BARBOSA, C. P.; et al. A utilização de jogos como metodologia de ensino da Matemática: uma experiência com alunos do $6^{\circ}$ ano do Ensino Fundamental

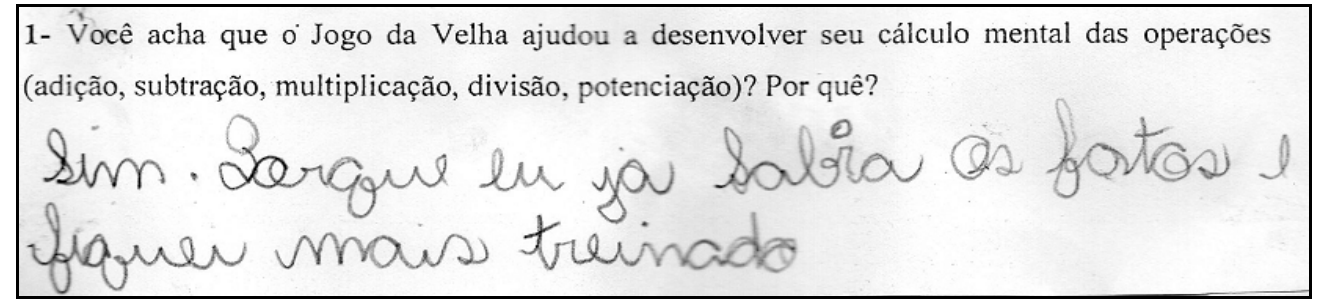

Figura 4 - Resposta do Aluno 2 a Questão 1 do questionário dos alunos Fonte: Imagem digitalizada pelos autores.

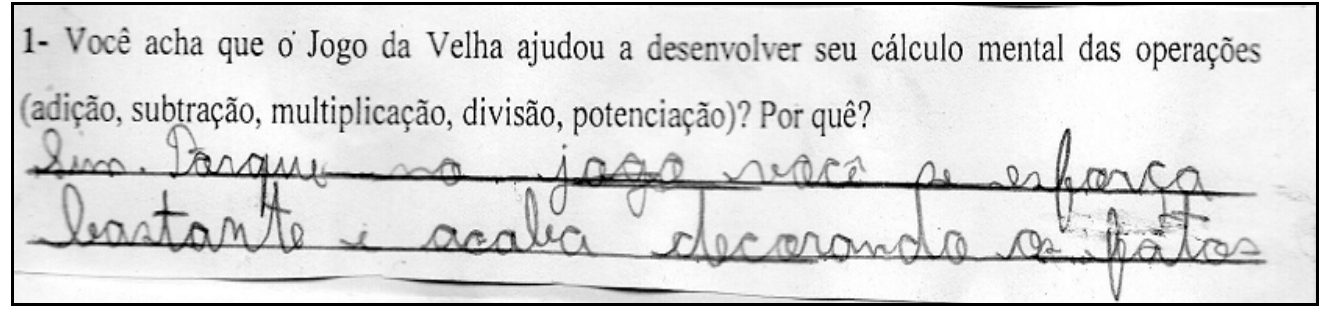

Figura 5 - Resposta do Aluno 3 a Questão 1 do questionário dos alunos Fonte: Imagem digitalizada pelos autores.

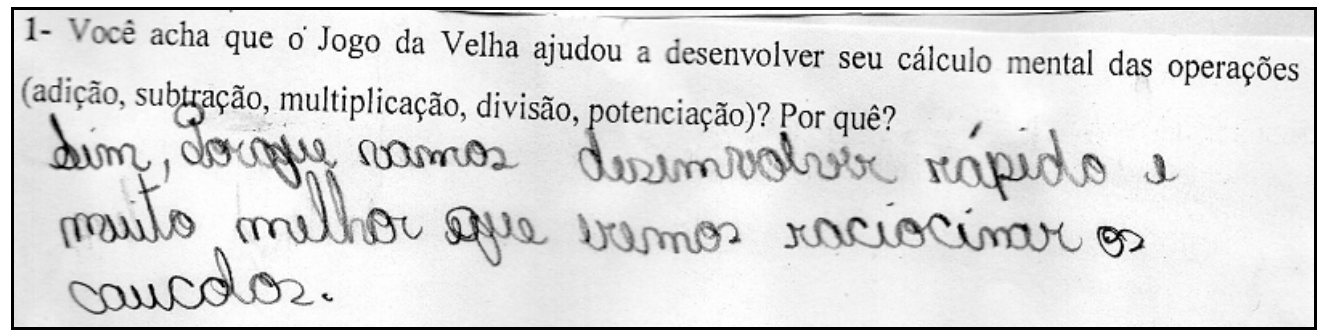

Figura 6 - Resposta do Aluno 4 a Questão 1 do questionário dos alunos

Fonte: Imagem digitalizada pelos autores.

Os alunos foram questionados sobre as dificuldades obtidas ao realizar o jogo. Seis discentes citaram dificuldades no algoritmo da divisão e a necessidade de contar nos dedos para efetuar as operações.

Ao percebermos essas dificuldades relatadas pelos discentes, nós os estimulamos a pensar mentalmente no resultado da operação partindo do conhecimento de resultados de operações que os alunos já tinham. Por exemplo, percebemos dificuldade do aluno em dizer o resultado de $9 \times 6$, perguntamos a ele o resultado de $9 \times 5$, cálculo mental que a maioria dos discentes possuem mais facilidade de lembrar seu resultado, e após sua resposta argumentamos que $9 \times 6=(9 \times 5)+9$. Propomos ao aluno acrescentar 10 ao resultado de $9 \times$ 5 e subtrair 1 encontrando o resultado de $9 \times 6$.

Através da discussão, os estudantes tiveram a oportunidade de apresentar as operações utilizadas por eles para toda turma, percebemos a autonomia e autoconfiança que o momento 
BARBOSA, C. P.; et al. A utilização de jogos como metodologia de ensino da Matemática: uma experiência com alunos do $6^{\circ}$ ano do Ensino Fundamental

trouxe para os alunos. Por meio da autoestima do aluno de contribuir na construção da tabela, valorizamos o próprio conhecimento do aluno.

A potenciação em relação às outras operações (adição, subtração, multiplicação e divisão) foi pouco citada pelos alunos. Em resultados oportunos, os alunos eram instigados a pensar na operação de potenciação, como descrevemos para o resultado 32:

- "Quais operações vocês utilizaram para encontrar o resultado 32?”

- “Oito vezes quatro”, responderam os alunos.

- "Pensaram em outra operação?”

- “Não", responderam os alunos.

Então, escrevemos os números 1, 2, 3, 4, 5, 6 e 5, 6, 7, 8, 9, 10 - presentes nos dados do jogo - em um canto da lousa.

- "Agora, utilizando a operação de potenciação, pensem em dois números que terá como resultado 32 ".

Parte dos alunos preferiu utilizar o cálculo escrito para resolver a situação proposta, outros apresentaram dúvidas de como realizar o algoritmo da potenciação necessitando da ajuda dos pesquisadores. Após todos os discentes encontrarem os dois números que satisfaziam o problema, perguntamos a eles os números escolhidos:

- "São o dois e o cinco", responderam os alunos.

- "Por quê?"

- "Porque dois elevado a cinco dá trinta e dois", respondeu um aluno.

- "Todos concordam?"

- "Sim”, responderam os alunos.

Durante a discussão das operações, constatamos dificuldades de alguns alunos em manterem a disciplina. Parte dos alunos não aguardava o colega terminar de falar para posteriormente se pronunciar, em alguns momentos, expressava em um tom de voz acima do necessário. Isso nos revela a falta de hábito dos alunos de participar de momentos que englobam a participação conjunta de toda turma.

Nos registros das operações dos alunos, em sua maioria, verificamos a associação correta entre números dos dados, operação e resultado. Essa análise satisfatória dos registros dos estudantes complementa a comprovação do alcance dos objetivos da atividade.

Contudo, o registro dos alunos no jogo também é uma maneira de detectar possíveis concepções errôneas. Através do registro de três duplas de alunos durante o jogo, detectamos 
BARBOSA, C. P.; et al. A utilização de jogos como metodologia de ensino da Matemática: uma experiência com alunos do $6^{\circ}$ ano do Ensino Fundamental

uma possível concepção errônea da comutatividade da subtração para esses alunos. A seguir, colocamos parte do quadro do registro das três duplas de alunos que apresentaram o erro.

\begin{tabular}{||l|l|c|}
\hline DADOS & OPERAÇÃO & RESULTADO \\
\hline $10-6$ & $10-6$ & 4 \\
\hline $5-5$ & $5-5$ & 0 \\
\hline 53 & $5-3$ & 8 \\
\hline & & 1 \\
\hline 67 & $6-7$ & 27 \\
\hline 93 & $9-3$ & 27 \\
\hline
\end{tabular}

Figura 7 - Registro das operações da dupla 1 Fonte: Imagem digitalizada pelos autores.

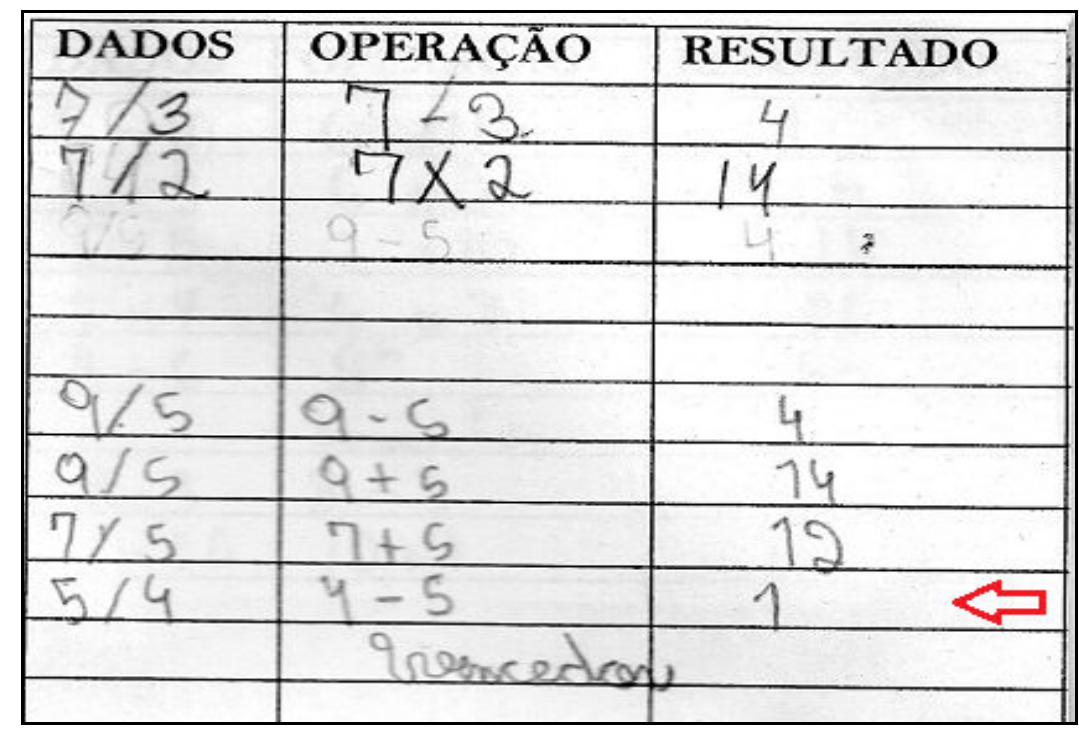

Figura 8 - Registro das operações da dupla 2 Fonte: Imagem digitalizada pelos autores.

\begin{tabular}{||c|c|c|}
\hline DADOS & OPERAÇÃO & RESULTADO \\
\hline 27 & $2+7=9$ & 9 \\
\hline 5,2 & $5+2=$ & 7 \\
\hline 377 & $3-7$ & $43<$ \\
\hline
\end{tabular}

Figura 9 - Registro das operações da dupla 3 Fonte: Imagem digitalizada pelos autores.

As respectivas operações registradas pelas duplas foram: $6-7=1,4-5=1$ e $3-7=$ 4. Consideramos relevante o professor salientar que - no caso dos números naturais - a 
BARBOSA, C. P.; et al. A utilização de jogos como metodologia de ensino da Matemática: uma experiência com alunos do $6^{\circ}$ ano do Ensino Fundamental

comutatividade é válida somente para adição e multiplicação, de forma que os alunos não aprendem - erroneamente - tal propriedade.

Quando questionamos os alunos sobre a utilização de jogos na sala de aula, alguns afirmaram que é um modo diferente de aprender, destacaram a natureza lúdica do jogo e a motivação para a aprendizagem. A seguir, destacamos a opinião de um aluno sobre a aplicação de jogos nas aulas.

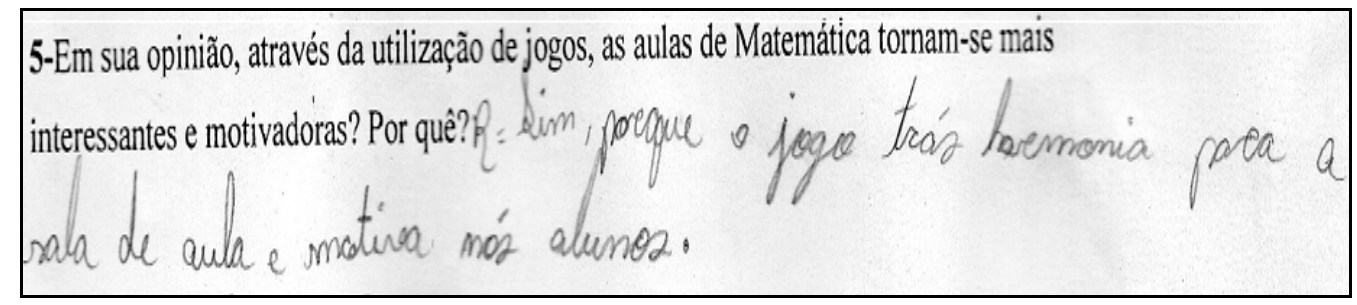

Figura 10 - Resposta do aluno 5 a Questão 5 do questionário dos alunos Fonte: Imagem digitalizada pelos autores.

A professora da turma destacou algumas vantagens da aplicação do Jogo da Velha, a saber: fixação das operações, atividade em dupla, aula prática e diversificada. A docente não citou desvantagens da atividade. De acordo com a professora, houve mudança de comportamento dos discentes no decorrer do jogo, uma delas é mencionada a seguir.

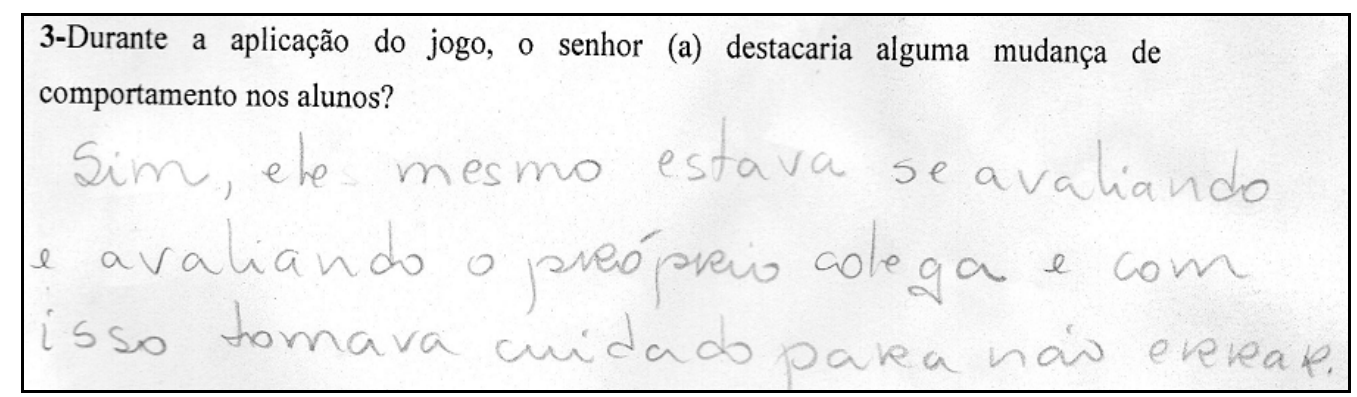

Figura 11 - Resposta da professora da turma a Questão 3 do questionário Fonte: Imagem digitalizada pelos autores.

A nosso ver, a avaliação do aluno de sua resposta é uma etapa da resolução de problemas, evidenciando uma das semelhanças do jogo a essa tendência metodológica, como defendido por Grando (2000).

Como futuros professores, entendemos que os resultados apresentados na atividade com o Jogo da Velha nos incentivaram a utilizar jogos no ensino da Matemática, que além do caráter lúdico, pode ser um recurso metodológico ao ensino. 
BARBOSA, C. P.; et al. A utilização de jogos como metodologia de ensino da Matemática: uma experiência com alunos do $6^{\circ}$ ano do Ensino Fundamental

\section{CONCLUSÃO}

Consideramos que a aplicação da atividade do Jogo da Velha gerou resultados satisfatórios. Os objetivos colocados para a proposta - desenvolvimento do cálculo mental, raciocínio lógico e percepção visual - foram alcançados.

O questionário foi útil para verificação dos objetivos. Ao serem perguntados se o Jogo da Velha ajudou a desenvolver o cálculo mental das operações (adição, subtração, multiplicação, divisão e potenciação), todos os alunos se manifestaram positivamente, inclusive os discentes que descreveram dificuldades na resolução de algumas operações do jogo. Em relação a esse grupo de alunos, acreditamos que tal atitude justifica-se pela oportunidade de tirar dúvidas com o colega no contato direto do jogo e menor constrangimento de apresentar suas dúvidas aos pesquisadores no decorrer da atividade.

Contudo, não acreditamos que somente o uso do Jogo da Velha é suficiente. A discussão das operações utilizadas pelos discentes potencializou o trabalho com as operações matemáticas. Naquele momento, evidenciamos que um resultado não é fixado em um único algoritmo, podendo ser obtido com diferentes operações.

Nesse sentido, a funcionalidade do registro das operações nessa atividade também merece ser destacada. O registro trouxe a ligação do jogo ao conteúdo na linguagem da Matemática para o aluno e neste trabalho também foi o instrumento que possibilitou detectar uma possível concepção errônea da comutatividade da subtração. Assim, consideramos relevante o docente insistir na realização do registro por parte dos alunos durante o desenvolvimento do jogo.

Além dos objetivos da proposta outras vantagens mais gerais do jogo foram observadas. Dentre elas, a motivação dos alunos para a aprendizagem, sua participação ativa no decorrer da atividade, a socialização com os colegas e a mudança de postura do professor, que passa de detentor do conhecimento para mediador da aprendizagem dos alunos (vivenciada pelos pesquisadores envolvidos nesta investigação).

Os benefícios tidos da ocorrência desta experiência instigam-nos a propor novas atividades que tragam o jogo para a sala de aula, sejam em atividades de estágio ou em futuras oportunidades no ofício de professores. 
BARBOSA, C. P.; et al. A utilização de jogos como metodologia de ensino da Matemática: uma experiência com alunos do $6^{\circ}$ ano do Ensino Fundamental

\section{REFERÊNCIAS}

BORIN, J. Jogos e resolução de problemas: uma estratégia para as aulas de Matemática. 6. ed. São Paulo: IME-USP, 2007.

BRASIL. Secretaria de Educação Fundamental. Parâmetros Curriculares Nacionais: matemática. Brasília, DF: MEC/SEF, 1998. Disponível em: <http//:portal.mec.gov.br/seb/ arquivos/pdf/matemática.pdf>. Acesso em: 2 ago. 2014.

GRANDO, R. C. O conhecimento matemático e o uso de jogo na sala de aula. 2000. $239 \mathrm{f}$. Tese (Doutorado em Educação Matemática) - Faculdade de Educação, Universidade Estadual de Campinas, Campinas, 2000. Disponível em: $<$ www.bibliotecadigital.unicamp.br/document /list.php?tid=7>. Acesso em: 5 ago. 2014.

MENEZES, J. E.; FOSSA, J. A. Razões sócio-histórico-filosófico-científicas para usar jogos no contexto ensino-aprendizagem de Matemática. In: ENCONTRO NACIONAL DE EDUCAÇÃO, 7., 2004, Recife. Anais eletrônicos... Recife: SBEM, 2004. p. 1-10. Disponível em: < http//:www.sbem.com.br/files/viii/pdf/07/2CC19453574449.pdf > . Acesso em: 6 ago. 2014.

MOREIRA, A. M.; MASINI, E. F. S. A aprendizagem significativa: a teoria de David Ausubel. 2. ed. São Paulo: Centauro, 2011.

NACARATO, A. M. Eu trabalho primeiro no concreto. Revista de Educação Matemática, ano 9, n. 9-10, p. 1-6, 2005.

STRAPASON, L. P. R; BISOGNIN, E. Jogos pedagógicos para o ensino de funções no primeiro ano do ensino médio. Bolema, Rio Claro, SP, v. 27, n. 46, p. 579-595, ago. 2013. Disponível em: $<$ http//:sites.unifra.br/.../Lisie\%20Pippi\%20Strapason_Dissertação\%20d >. Acesso em: 11 ago. 2014.

UNIVERSIDADE SEM FRONTEIRAS. Atividades de laboratório de ensino de matemática. Maringá, PR, 2009. Disponível em: <http://www.dma.uem.br/matemativa/ texto2.pdf $>$. Acesso em: 25 jun. 2014.

Recebido em: 24/10/2014

Aprovado em: 02/12/2014

Publicado em: 29/06/2015 